\title{
Indications and benefits of intraoperative esophagogastroduodenoscopy
}

\author{
Martin Stašek ${ }^{1}$, René Aujeský ${ }^{1}$, Radek Vrba ${ }^{1}$, Martin Loveček ${ }^{2}$, Josef Chudáček ${ }^{2}$, Petr Janda ${ }^{2}$, Michal Gregořík ${ }^{1}$, \\ Katherine Vomáčková ${ }^{2}$ Čestmír Neoral², Dušan Klos ${ }^{1}$ \\ ${ }^{1}$ Department of Surgery I, University Hospital, Olomouc, Czech Republic \\ ${ }^{2}$ Department of Surgery I, Faculty of Medicine and Dentistry, Palacky University, Olomouc, Czech Republic
}

Videosurgery Miniinv 2018; 13 (2): 164-175 DOI: https://doi.org/10.5114/wiitm.2018.72740

\begin{abstract}
Introduction: Intraoperative esophagogastroduodenoscopy (IOG) is a diagnostic and therapeutic method for a variety of special conditions in upper gastrointestinal (UGI) pathology. The indication remains individual due to insufficient evidence and limited training of surgeons in digestive endoscopy.

Aim: To evaluate the indications, benefits and risks of IOG.

Material and methods: A single-center retrospective study of 110 consecutive IOGs in 104 patients was performed. The preoperative plan, the timing of IOG, preoperative evaluation, intraoperative finding, localization of the pathology, type of the procedure, change of expected therapy and complications were assessed.

Results: The cohort comprised 29 esophageal tumors, 5 tumors of the cardia, 36 gastric tumors, gastrointestinal bleeding (8), esophageal diverticula (3), perforations (3), GERD (5), mediastinal pathology (3), fistula (4), assessment of nutrition (10), duodenal adenoma (2), ulcer disease, esophageal stenosis and gastric volvulus. The indication for IOG was established preoperatively in $79 \%$ and intraoperatively in $21 \%$. The lesion was localized in $96.4 \%$. The therapy was altered to a wider resection (11), smaller resection (5), localization and surgical therapy of bleeding (8) or allowed minimally invasive surgery (25). A total of 3 postoperative complications included gastric perforation and positivity of resection line (following EMR/ESD) and recurrent bleeding. The 30-day mortality reached 3.6\% without a specific cause in IOG. Conclusions: The IOG is a complementary method in the diagnosis and treatment of UGI pathology. It enables minimally invasive finalization of the procedures and individualization of the therapy.
\end{abstract}

Key words: intraoperative upper endoscopy, laparoscopic endoscopic cooperative surgery, gastric and esophageal tumors.

\section{Introduction}

Intraoperative esophagogastroduodenoscopy (IOG) is a diagnostic and therapeutic modality with multiple purposes. There are significant differences between surgical departments and individual surgeons regarding the indications for IOG, with questionable possibility to evaluate the benefit.

\section{Aim}

The aim of our work is to evaluate the indications for IOG, to compare our experience with information in the literature and establish options for current clinical use.

\section{Material and methods}

The authors present a retrospective study of 110 IOGs in 104 patients indicated for gastroscopy in the operating room under general anesthesia. The data were collected from the documentation and patient information and preoperative and intraoperative findings including preoperative plan, timing of IOG, preoperative evaluation of the specific pathology, in-

\section{Address for correspondence}

Dušan Klos MD, PhD, Department of Surgery I, University Hospital, 6 I.P.Pavlova St, 77900 Olomouc, Czech Republic,

phone: +42 776308054, e-mail: dklos@seznam.cz 
traoperative finding and localization of the pathology, type of endoscopic procedure and surgical procedure, change of the preoperatively expected procedure and approach. Postoperatively, complication and pitfalls of the endoscopy and 30-day survival were assessed. In individual indications, the number of intraoperative endoscopies was correlated with the total number of related procedures to highlight the specific indication for the intraoperative approach.

\section{Results}

The indications for IOG according to the preoperative documentation are listed in Figure 1.

\section{Benign esophageal conditions}

Indications in gastroesophageal reflux disease (GERD) comprised evaluation of re-do operations in 2 patients and other pathologies (intramural processes, diverticula) in 3 patients. In this period, we performed 502 procedures for GERD.

The IOG was indicated to identify the level of the caustic esophageal stenosis and healthy mucosa with subsequent colonic conduit replacement. The fistula management included exact localization and navigation of surgery in a patient after sleeve gastrectomy with gastropleurobronchial fistula and evaluation of the fistula tract following resection of esophageal diverticula during thoracostomy using vacuum therapy.

Suspected perforation included one case of pneumomediastinum, one case of iatrogenic perforation in suspected Zenker's diverticulum (from another facility) and perforation of the stomach following laparoscopic fundoplication.

\section{Esophageal tumors}

The indication of IOG in esophageal tumors (Figure 2) followed the idea of localization of the process and navigation of the surgery in the majority of cases, especially in mesenchymal intramural tumors and early, non-palpable tumors. In early tumors the definitive decision between endoscopic and surgical treatment can be managed. The further indication was dysphagia with previously missed tumor of cervical esophagus and advanced cancer in order obtain the pathology specimen to decide about the further strategy to obtain nutrition and to determine the oral border of the tumor. Two hundred and thirty esophagectomies were completed during the period.

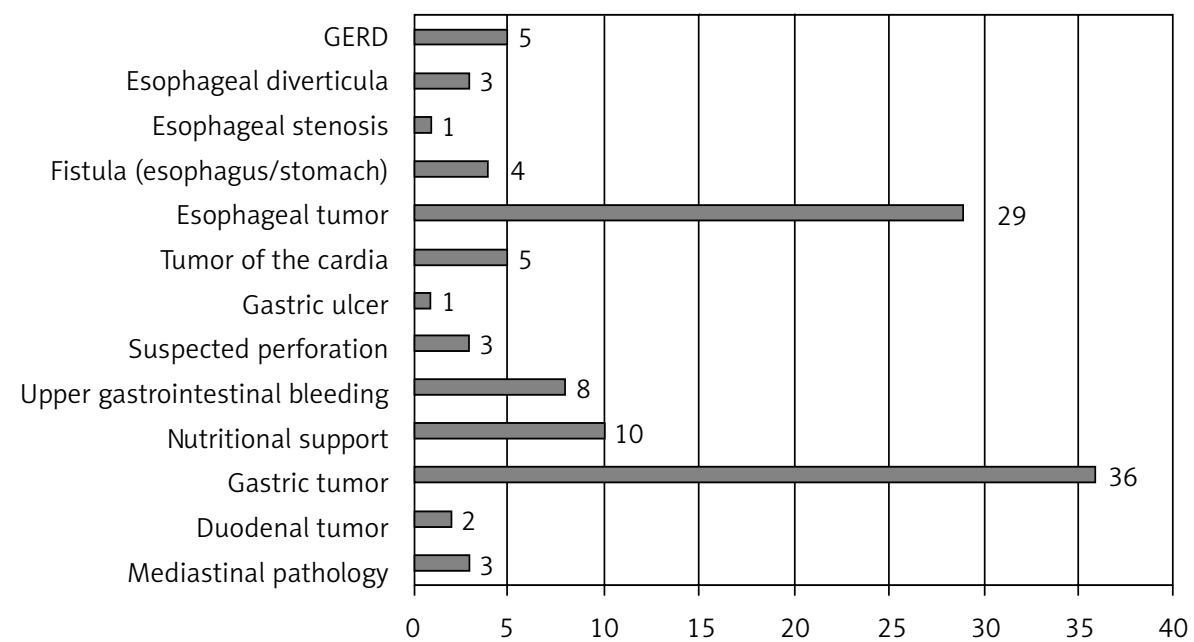

Figure 1. Indications for intraoperative esophagogastroduodenoscopy

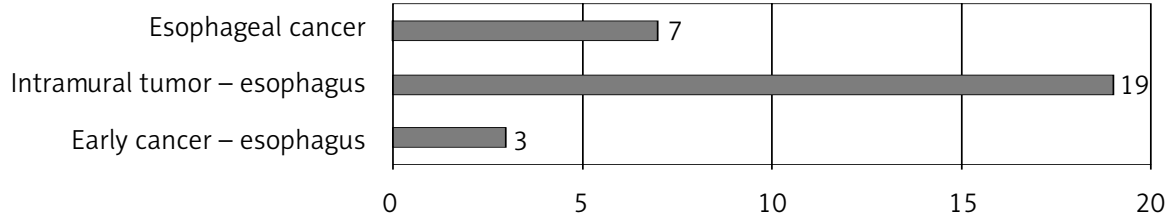

Figure 2. Esophageal tumor types indicated for intraoperative esophagogastroduodenoscopy 


\section{Upper gastrointestinal bleeding}

Upper gastrointestinal bleeding included 8 cases, 5 cases of spontaneous bleeding (3 duodenal ulcer bleedings, 1 small bowel and 1 colonic bleeding) and 3 postoperative cases (bleeding following fundoplication, pancreatogastric anastomosis and bleeding from the esophageal conduit after esophagectomy).

\section{Nutritional support}

Nutritional support was indicated in 10 patients. It comprised high-risk indications for percutaneous endoscopic gastrostomy (PEG) (3 cases - postoperative states, high-risk patient, a combination with other operation) and uncertain possibility to provide PEG (finalized by open gastrostomy - 3 cases) and extraction of migrated stents (3 cases). In 1 case, impaired gastric emptying with stenosis of palliative gastroenteroanastomosis was evaluated. During the study period, we performed 110 gastrostomies and 272 PEGs.

\section{Gastric and duodenal tumors}

The spectrum of gastric tumors is presented in Figure 3. In this period, we performed gastric resection for cancer in 284 cases. Operated intramural tumors comprised 28 cases, requiring 14 open and 14 laparoscopic procedures. Carcinoids were treated using the technique of endoscopic mucosal resection, in the first case as a sole endoscopy, in the second case during distal pancreatectomy due to pancreatic mass.

Duodenal tumors included 1 case of adenoma with high-grade dysplasia and 1 case of typical carcinoid.

\section{Mediastinal pathologies}

Mediastinal pathologies included 1 cystic formation and 2 mediastinal abscesses.

\section{Strategy and purposes of IOG}

The indication for IOG was established preoperatively in $87 / 110$ cases, and peroperatively in 23 cases. The peroperative indications comprised localization of a non-palpable tumor (15), bleeding with failed localization (2), localization of the perforation (3) and individual indication (nasojejunal tube placement, stent indication, evaluation of the gastric morphology).

Successful localization of the lesion was achieved in 98\% (108 patients). The localization failed in 2 cases - perforation after laparoscopic fundoplication and metastasis in the small bowel in gastric carcinoma (intraoperatively confirmed systemic disease).

Significant new or changed findings were present in 26 endoscopies (Table I).

\section{Endoscopic termination of the procedure}

The endoscopic procedures included 79 diagnostic endoscopies with possible biopsy, which included verification of mucosal trauma (13) and suture leak (12). The polyp was removed in 22 cases, using various technical methods (polypectomy/endoscopic mucosal resection/endoscopic submucosal dissection in 6/7/9 cases respectively). Further endoscopies included hemostasis (argon-plasma coagulation, injection hemostasis - 2 patients), foreign body extraction (stent), esophageal abscess incision, enteral tube placement and percutaneous endoscopic gastrostomy (4 cases).

Sole endoscopy was performed in 20 (18\%) cases, finalized with the endoscopic alternative of therapeutic possibilities, as listed in Table II.

\section{Results of endoscopy-assisted surgery}

The list of final surgical procedures is presented in Table III, dividing the indications following the localization and general indication for therapy.

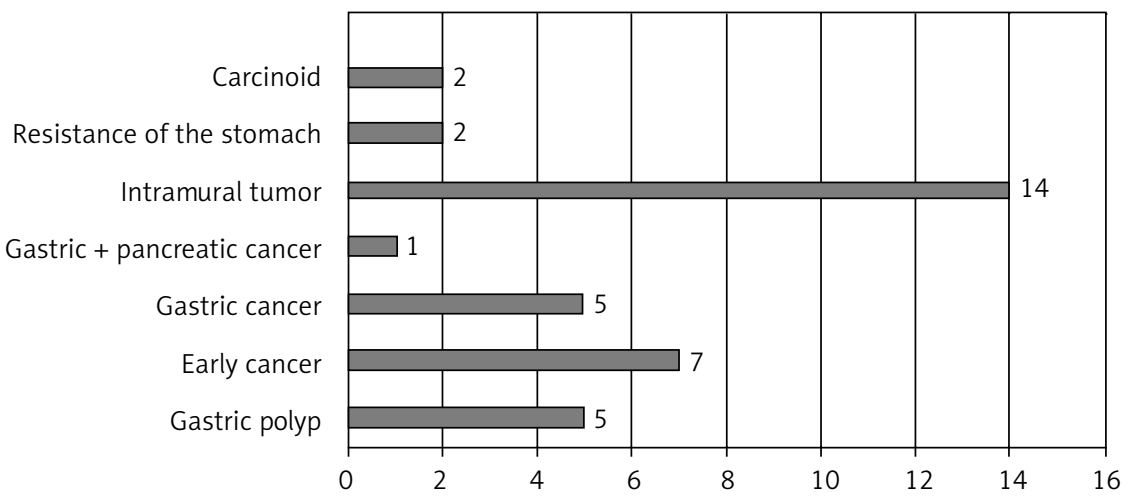

Figure 3. Gastric tumor types indicated for intraoperative esophagogastroduodenoscopy 
Table I. New findings in the intraoperative esophagogastroduodenoscopy

\begin{tabular}{|c|c|c|c|}
\hline New finding $-\sum$ & Diagnosis & New/changed finding & $N$ \\
\hline \multirow{7}{*}{$\begin{array}{l}\text { New diagnosis } \\
\sum=9\end{array}$} & Up-side down stomach & Esophageal diverticulum & 2 \\
\hline & Postoperative peritonitis & Reflux esophagitis & 1 \\
\hline & Unclear dysphagia & Esophageal/hypopharyngeal tumor & 2 \\
\hline & Gastric GIST & Esophageal cyst & 1 \\
\hline & GERD & Esophageal intramural tumor & 1 \\
\hline & Failed nutrition (neurologic etiology) & Gastric volvulus & 1 \\
\hline & Dyspepsia, cholelithiasis & Gastric polyps & 1 \\
\hline \multirow{4}{*}{$\begin{array}{l}\text { Exclusion of presumptive } \\
\text { diagnosis } \sum=6\end{array}$} & Small bowel metastasis & Extraluminal impression & 2 \\
\hline & Zenker's diverticulum & & 1 \\
\hline & Intramural tumor & & 2 \\
\hline & Mallory-Weiss syndrome & & 1 \\
\hline \multirow{2}{*}{$\begin{array}{l}\text { Changed diagnosis } \\
\sum=3\end{array}$} & Mediastinal abscess & Esophageal intramural abscess & 2 \\
\hline & Intramural tumor of the esophagus & Intramural hematoma of the esophagus & 1 \\
\hline \multirow{4}{*}{$\begin{array}{l}\text { Changed localization } \\
\sum=4\end{array}$} & Esophageal tumor & Tumor of the cardia & 1 \\
\hline & Esophageal tumor & Overgrowth to the stomach & 1 \\
\hline & Tumor of the gastric antrum & Tumor of the gastric body & 1 \\
\hline & Tumor of the cardia & Carcinoma in extensive BE & 1 \\
\hline \multirow{4}{*}{$\begin{array}{l}\text { Localization of } \mathrm{Gl} \\
\text { bleeding } \sum=4\end{array}$} & Gastric conduit bleeding & Colonic bleeding & 1 \\
\hline & Gastric ulcer & & 1 \\
\hline & Small bowel bleeding & & 1 \\
\hline & $\begin{array}{c}\text { Excluded gastric and small bowel } \\
\text { bleeding }\end{array}$ & & 1 \\
\hline
\end{tabular}

GIST - gastrointestinal stromal tumor, GERD - gastroesophageal reflux disease, BE - Barrett's esophagus.

Comparing the preoperative plans from the ment, the IOG necessitated conversion to open documentation and final technique and results surgery in 5 cases. Increase and gross change of of the surgical therapy, we gained information the resection extent resulted in the decision for about the change in surgical approach (Figure 4). enucleation to esophagectomy, total gastrectomy Despite the support of minimally invasive treat- (TGE) to esophagectomy, esophagectomy to TGE

Table II. Endoscopic finalization of the therapy

\begin{tabular}{|llcc|}
\hline Diagnosis & $\sum$ & Endoscopic therapy & No. \\
\hline Barrett's esophagus/early esophageal cancer & 4 & EMR/ESD & $3 / 1$ \\
\hline Intramural tumor of the esophagus & 2 & DG/ESD & $1 / 1$ \\
\hline Gastric polyp & 3 & Polypectomy/EMR & $2 / 1$ \\
\hline Tumor of the cardia & 2 & EMR/ESD & $1 / 1$ \\
\hline Early gastric cancer & 3 & ESD & $1 / 1 / 1$ \\
\hline Intramural gastric tumor & 2 & Endoscopic incision & 2 \\
\hline Intramural abscess of the esophagus & 1 & PEG & 1 \\
\hline Failed peroral nutrition & 3 & 3 \\
\hline
\end{tabular}

EMR - endoscopic mucosal resection, ESD - endoscopic submucosal dissection, DG - diagnostic gastroscopy, PEG - percutaneous endoscopic gastrostomy. 
Martin Stašek, René Aujeský, Radek Vrba, Martin Loveček, Josef Chudáček, Petr Janda, Michal Gregořík, Katherine Vomáčková, Čestmír Neoral, Dušan Klos

Table III. Surgical intervention

\begin{tabular}{|c|c|c|}
\hline Type of surgery/ $\Sigma$ & Procedure & Number \\
\hline \multirow{5}{*}{$\begin{array}{l}\text { Esophageal surgery } \\
\sum=32\end{array}$} & GERD surgery (fundoplication, gastropexy) & 6 \\
\hline & Resection of diverticulum (TS/TT/additive to GERD) & $3(1 / 1 / 1)$ \\
\hline & Esophagectomy & 6 \\
\hline & Enucleation of esophageal tumor (TS/LS/TT) & $17(13 / 2 / 2)$ \\
\hline & Esophageal wall abscess drainage/perforation suture & $1 / 1$ \\
\hline \multirow{3}{*}{$\begin{array}{l}\text { Gastric surgery } \\
\sum=26\end{array}$} & LS enucleation/wedge resection (LS/open) & $2 / 16(11 / 5)$ \\
\hline & Gastric resection (Billroth I/Billroth II/TGE) & $7(2 / 1 / 4)$ \\
\hline & Excision of fundal fistula, plombage, jejunostomy & 1 \\
\hline $\begin{array}{l}\text { Duodenal surgery } \\
\sum=2\end{array}$ & Wedge resection & 2 \\
\hline $\begin{array}{l}\text { Nutrition } \\
\sum=7\end{array}$ & Gastrostomy/migrated stent extraction/GEA correction & $3 / 3 / 1$ \\
\hline \multirow{2}{*}{$\begin{array}{l}\text { Bleeding control } \\
\sum=8\end{array}$} & Enterotomy, duodenotomy, cross ligature & 3 \\
\hline & Revisional surgery (re-bleeding/dehiscence/postoperative bleeding) & $1 / 1 / 3$ \\
\hline $\begin{array}{l}\text { Exploration } \\
\sum=3\end{array}$ & Laparotomy/thoracotomy & $2 / 1$ \\
\hline \multirow{2}{*}{$\begin{array}{l}\text { Other procedures } \\
\sum=12\end{array}$} & Thoracic (tracheostomy, mediastinoscopy, thoracostomy, lung decortication) & 5 \\
\hline & Abdominal (cholecystectomy, bowel resection, liver resection, pancreatic resection) & 7 \\
\hline
\end{tabular}

GERD - gastroesophageal reflux disease, LS - laparoscopy, TS - thoracoscopy, TT - thoracotomy, TGE - total gastrectomy, GEA - gastroenteroanastomosis.

( 2 cases), extension of the esophageal resection to the stomach, TGE in non-palpable tumor (3 cases), wedge resection to Billroth I, diverticulectomy and wedge resection enlargement (2 cases). Decreased resection included proximal gastrectomy to wedge resection and targeted and decreased wedge resections of the stomach and duodenum. The operation was cancelled in 1 case and preoperatively planned esophageal or gastric resection was omitted in 4 cases (followed by other planned surgery).
The IOG-related morbidity was identified in 3 cases - positivity of the resection line following endoscopic mucosal resection, recurrent bleeding and perforation following endoscopic submucosal dissection requiring surgical revision.

General 30-day mortality of the group undergoing IOG was 3.6\% (4 patients). Causes included pulmonary embolism, heart failure with pulmonary edema, respiratory failure and multiple organ failure following gastric conduit necrosis after esophagectomy. No causal connection to the IOG was proven.

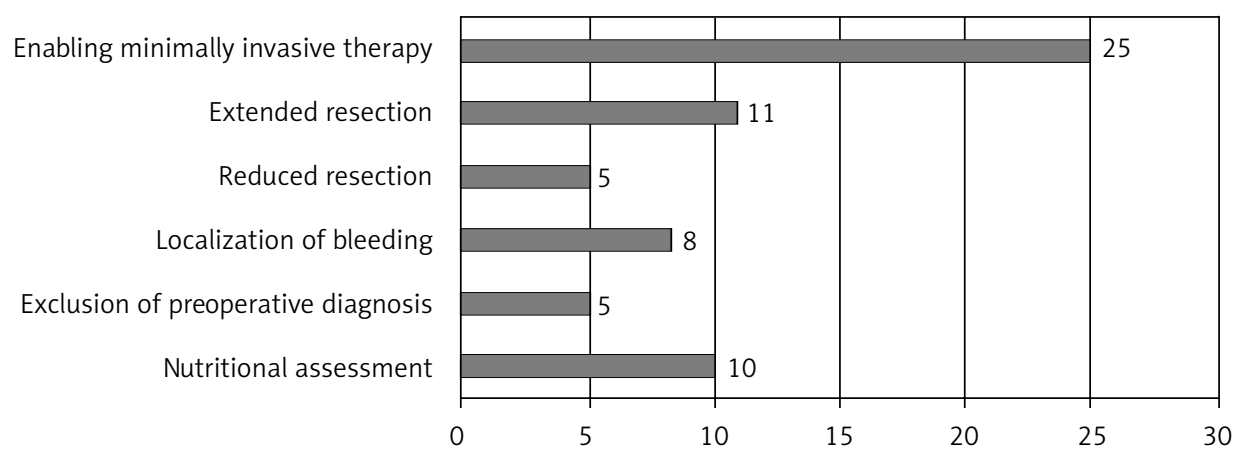

Figure 4. Changes in the surgical approach based on intraoperative endoscopy 


\section{Discussion}

The history of intraoperative use of various endoscopic methods comprises a wide spectrum of possibilities including gastroscopy, colonoscopy, cholangioscopy, enteroscopy, endoscopic ultrasound (EUS) and endoscopic retrograde cholangiopancreatography (ERCP).

General indications for IOG include planned endoscopic procedures with high risk of surgical complications, pathology with the alternative of both endoscopic and surgical therapy, failure to localize the pathological process, new intraoperative finding, evaluation of the anastomosis and management of anastomotic insufficiency, intraoperative navigation of the surgery and decreased patient's compliance (including pediatric indication) [1] and patient's wishes. The IOG should not replace inadequate preoperative evaluation.

\section{General strategy of IOG}

The approach to the indication of IOG can be absolute or selective. The absolute approach means endoscopic performance in all specific pathologies (e.g. GIST) or all specific procedures (e.g. gastric sleeve, total gastrectomy, re-do fundoplications). Our preferred approach is selective use in preoperatively discussed patients with uncertainties in the preoperative workup and intraoperative decision-making. We are more likely to perform non-selective IOG in esophageal or gastric intramural tumors, esophageal diverticula (middle and lower esophagus), re-do fundoplications and early-stage gastric and esophageal tumors. Bariatric procedures and endoscopic procedures on the biliary tree were excluded from the observed group.

Preoperative indications are more frequent. The intraoperative decision for IOG means a certain delay due to organization and personnel requirements. This is the place for a strong recommendation of training of upper Gl surgeons in digestive endoscopy [2-4] comprising both diagnostic and therapeutic modalities (percutaneous endoscopic gastrostomy, polypectomy, endoscopic mucosal resection and endoscopic submucosal dissection, endoscopic hemostasis, foreign body extraction, tube placement, etc.). The endoscopist should obtain sufficient knowledge of the surgical approach and assessment of the surgical complications and postoperative situations.

The IOG localizes the pathology in the vast majority of cases. The main advantage of IOG can be appreciated in non-palpable lesions, pathology in a problematic localization (cardio-esophageal junction, posterior gastric wall, esophagus and mediastinum) and in the absence of tactile verification. Main reasons for failed localization in sole endoscopy are perforation and changed situation due to the healing process (ulcer, early cancer, incomplete endoscopic removal of early tumors indicated for limited resection). In the case of bleeding it can be a different location of the bleeding process, massive bleeding and small lesions (e.g. Dieulafoy ulcer). Preoperative endoscopy offers various possibilities of marking of the lesions including dye spot marking [5], autologous blood marking [6], clip placement [7-9], computed methods [10] or acceptance of preoperative endoscopic evaluation by the endoscopist [11].

\section{New findings during IOG}

New findings during endoscopy may be of various importance. Highly important are findings of changed localization of the pathology leading to a different surgery; different findings recognized during cooperation of the surgeon and endoscopist could lead to the definitive decision about treatment modality (additive surgery, endoscopic versus surgical therapy). The majority of intraoperative decision-making strategies could be prevented with preoperative EUS (evaluation of the depth of invasion in early cancer, intramural abscesses and tumors) or preoperative endoscopy. The necessity of weighting further diagnostic methods and cooperative decision making is obvious.

\section{Endoscopic termination of the procedure}

The endoscopic finalization of the procedure varies from diagnostic gastroscopy and standard procedures for nutritive support (peroral endoscopic gastrostomy, jejunal tube placement) to endoscopic tumor removal using the technique of endoscopic mucosal resection (EMR) or endoscopic submucosal dissection (ESD). Especially in the esophagus and cardia, even complete evaluation by EUS [12] may not reliably confirm the depth of invasion of early cancer. In the case of the non-lifting phenomenon, immediate continuation with the surgical procedure is possible. Further evidence should be gained in sentinel lymph node retrieval after endoscopic tumor resections. 
The number of endoscopically finalized procedures varies greatly according to the type of facility with a strongly decreased number in surgical departments without skilled endoscopists. A stronger tendency to indicate IOG in early tumors is observed in early esophageal and cardia tumors and gastric tumors in demanding locations (subcardial, fundal, lesser curvature); incomplete removal can be radicalized by surgery without significant risk increase. The exact identification of the overgrowth of cardia tumors into the esophagus remains an important issue, along with a potential to change the resection extent substantially.

The patient undergoing planned IOG and surgery should be preoperatively informed about both therapeutic possibilities. In the case of an intraoperative decision, it is with the objective to achieve the least invasiveness. In the majority of doubtful cases, we provide preoperative endoscopic evaluation, which decreases the necessity of IOG for non-selective use in specific pathologies.

\section{Benign esophageal conditions}

In GERD the main indications include suspected or proven local comorbidities (short esophagus [13-15], intramural tumors, diverticula [16]) with possible use of intraoperative manometry [17] and a special indication of re-do fundoplications for postoperative complications (suspected perforation, slipped Nissen, intrahiatal compression). The IOG technique requires securing of the esophagocardial junction, diaphragmatic impression, and translumination in adhesions after previous surgery. In some upper $\mathrm{Gl}$ surgery centers, IOG is required in revisional procedures.

The IOG in esophageal diverticula [18-20] offers help in the preparation phase, as leading for stapler placement and detection of insufficiency in the stapler line. Furthermore, the safety of the myotomy can be verified. In the case of stenosis, especially of caustic origin, endoscopy enables identification of the level of healthy mucosa and pertubability of the lumen of the oral part of the esophagus.

Fistula cases represent mostly postoperative fistulas. For diagnostic purposes, we expect localization of the fistula, measuring of the accessible part of the fistula, evaluation of the outlet part of the esophagus and stomach, quality of adjacent mucosa, and fistulography. For therapeutic purposes, we can pro- vide debridement and lavage, drainage, endoscopic vacuum assisted closure [21], clipping (using over the scope clips or hemoclips) [22], stent introduction [23] and local use of fibrin tissue glues [24], sometimes in combination or consecutively [25]. The endoscopic therapy requires repeated applications and endoscopic revisions. The potential surgical part contains suture with omental flap reinforcement, vacuum-assisted closure placement, surgical drainage or even resection, usually multiple staged. The combination of surgical and endoscopic interventions may increase the possibilities of minimally invasive therapy. Repeated endoscopies usually do not require endoscopy in the OR and a meaningful approach to the necessity of the combined approach has to be chosen.

\section{Esophageal tumors}

Esophageal tumors represent an important field for IOG. In epithelial tumors, endoscopy can offer additional diagnostic information in the unsatisfactory preoperative evaluation and in nonpalpable tumors, including the evaluation of completion of the removal and the resection line [26], and endoscopic removal in early tumors if the positive lifting phenomenon is observed [27, 28]. The sentinel lymph node can be localized after intra- or peritumoral injection of the tracer as a promising tool for targeted treatment of early tumors [29]. In advanced tumors especially of the upper esophagus, we can decide on stent placement (in our facility provided under $\mathrm{X}$-ray guidance) or nutritive jejunostomy/gastrostomy. Endoscopic navigation offers perfect localization of intramural tumors with possible translumination and evaluation of the mucosa during surgical removal, mostly enabling a minimally invasive approach [30]. In tumors of the cardia, the possibility of endoscopic mucosal resection may greatly decrease the burden of surgical exposure (even a combined abdominal and thoracic approach).

\section{Gastric ulcer, perforation of the upper gastrointestinal tract}

Non-complicated gastric ulcer is a rare indication for IOG, usually only in terms of elective operation and intraoperative verification of the healing process. Perforation is a doubtful indication for IOG. The diagnosis of spontaneous perforation (Boerhaave syndrome [31], gastric ulcer perforation, fissuration of the tumor) is usually established without the ne- 
cessity of endoscopic assistance, and despite endoscopic treatment possibilities (endoscopic omentoplasty [32], clipping, stenting) we still find surgery the gold standard of therapy in gastric ulcer and early Boerhaave syndrome. In the case of iatrogenic perforation, the recognition of perforation differs according to the localization and procedure [33-35]. Problematic diagnostic situations include perforation in Zenker's diverticulum, fundoplication and endoscopic submucosal dissection [36].

\section{Upper gastrointestinal bleeding}

Failed endoscopic therapy of upper gastrointestinal bleeding requires a cooperative approach of the surgeon, interventional radiologist and endoscopist [37]. The place for IOG is in massive bleeding disabling the localization of the bleeding (fundal varices, Dieulafoy ulcer [38], angiodysplasia [39], esophagocardial junction bleeding, bleeding from post-duodenal location) or in postoperative bleeding (post-pancreatectomy bleeding [40, 41] esophageal conduit bleeding, bleeding after fundoplication, sleeve gastrectomy [42] etc.). Gastroscopy without identification of the specific bleeding lesion may continue with intraoperative enteroscopy [43-45]. In the minority of surgical therapies, endoscopic therapy can be used (clipping of small ulcers, ligation of the esophageal component of gastroesophageal varices type GOV 1 and 2) usually as an adjunct to surgical therapy. In general, failed endoscopic hemostasis requires an appropriate surgical haemostatic technique as definitive treatment - ligation, resection, completion of the pancreatectomy, etc.

\section{Nutritional support}

The means for nutritional support (gastrostomy, stenting) are conventionally performed in local anesthesia following common indications [46, 47]. The cases indicated for performance in the OR include uncertain diagnosis (upper esophageal/hypopharyngeal tumors preoperatively misdiagnosed), general indisposition for sufficient compliance (mental retardation, panic disorder), complicated postoperative states with real risk of colonic/small bowel interposition, failed or complicated percutaneous endoscopic gastrostomy in the patient's history, states after gastric resection, and indications for other surgical procedures (tracheostomy etc.).

\section{Gastric and duodenal tumors}

In gastric tumors, the main advantage of IOG is in localization of the pathology (together with further advanced preoperative imaging and evaluation) [48], especially in small and non-palpable tumors, navigation of surgery, favorably in less synoptic locations (esophagocardial junction, lesser curvature, posterior gastric wall) [49]. In these locations of mesenchymal or early epithelial tumors (following EUS examination [50]) EMR/ESD or even the submucosal tunnelization technique could be indicated [51] with possible laparoscopic assistance. In the case of failed endoscopic treatment, immediate IOG-navigated limited resection [30, 49, 52, 53] with even increased safety may follow [54]. Proper navigation increases the probability of appropriate minimally invasive treatment; the specific technique varies from conventional laparoscopic and endoscopic cooperative surgery (LECS), inverted LECS, non-exposure techniques (CLEAN-NET) and even non-exposed endoscopic wall-inversion surgery (NEWS) [55]. Staple line or mucosal damage control is recommendable (air leak test, direct control, translumination) [56]; in our case series it was fully reliable as a predictor of suture leak. Contrarily, missed perforation in ESD procedures can appear postoperatively in up to $14 \%$ of cases [57].

In duodenal tumors, a meaningful indication of IOG remains in D1-D4 early tumors and polyps feasible for endoscopic [58] or partial surgical resection [59-62] in order to navigate surgery. In tumors within the papilla, the EUS should exclude patients suitable for surgical resection and identify neoplasms suitable for endoscopic resection of the papilla and double-duct drainage $[63,64]$. Further localization techniques include intraoperative ultrasound and EUS [65], especially in neuroendocrine tumors. The indication in duodenal tumors remains rare.

\section{Mediastinal pathology}

Most mediastinal pathologies require $\mathrm{CT}$ or PET CT scans and EUS (endobronchial and esophageal). The reliability of cytologic examination in these pathologies is questionable, despite promising, but limited, evidence in the literature $[66,67]$. Most of the indications for IOG include tumorous processes adjacent to the esophageal wall with a higher risk of esophageal damage (cystic lesions, neurogenic and mesenchymal tumors) [68], suspected abscesses of 
the esophageal wall and mediastinum with possible intraluminal drainage.

\section{Suture/anastomosis and mucosa control}

The importance of the evaluation of the suture, anastomosis and mucosa control is promising in minimally invasive approaches of upper GI surgery. Enucleation of esophageal and gastric intramural tumors carries the risk of mucosal damage and perforation. Manual or stapled anastomoses carry a certain risk of leakage. The risk is increased in vascular compromise and stapler line insufficiency. The vascular compromise can be evaluated by endoscopy with eventual indocyanine green viewing [69]. The way to evaluate the anastomosis may be only technical (color staining, air leak test under water level) [70] with questionable outcomes. Conveniently, IOG offers direct visual control with the air leak test, which can be enforced by navigation of the surgical suture or even endoscopic reinforcement of the insufficiency of the stapled anastomosis or suture (hemoclips, over-the-scope clips, endoscopic suture). The general scientific problem of insufficient evidence remains, with the exception of bariatric surgery, which offers large series of promising data $[71,72]$. The reliability of extrapolation to the oncosurgical anastomotic complication remains unclear [73].

\section{Navigation of sentinel lymph node harvesting}

Sentinel lymph node (SLN) harvesting in the upper gastrointestinal tract still remains of uncertain significance [74, 75]. The most appropriate way to evaluate the SLN remains endoscopic targeted injection, no matter which type of tracer we use. We have evaluated the sentinel lymph node in 2 patients with early esophageal cancer, in both with successful visualization [29, 76]. Further evolution of the tracer and image-guided lymphatic mapping seems to be promising for the future, including function-preserving gastric oncological surgery [77].

\section{Further indications for IOG}

Further IOG indications may include assistance in Heller myotomy for achalasia [78-80], volvulus of the stomach [81], duodenal diverticula [82], intraoperative foreign body extraction [83] and rare causes of bleeding [84, 85]. Pediatric indications are targeted in a more distinct way to inherited pathologies

Table IV. Concise list of possible indications of IOG following our and literature experience

\begin{tabular}{|c|c|c|c|c|c|c|}
\hline Variable & Diagnosis & $\begin{array}{c}\text { Further } \\
\text { specification }\end{array}$ & $\begin{array}{c}\text { Endoscopic } \\
\text { therapy }\end{array}$ & Navigation & $\begin{array}{l}\text { Anastomosis/ } \\
\text { complication }\end{array}$ & $\begin{array}{c}\text { Revisional } \\
\text { surgery }\end{array}$ \\
\hline GERD & SU & + & RE & RE & + & + \\
\hline Esophageal diverticula & + & ++ & N & ++ & ++ & ++ \\
\hline Suspected perforation & SU & SU & SU & SU & SU & SU \\
\hline Nutritional support & SU & SU & ++ & $\mathrm{N}$ & SU & SU \\
\hline Mediastinal pathology & $\mathrm{PO}$ & SU & N & SU & SU & SU \\
\hline Gastrointestinal bleeding & $\mathrm{PO} / \mathrm{SU}$ & SU & + & SU & SU & SU \\
\hline Esophageal tumor early & $\mathrm{PO}$ & + & + & + & SU & SU \\
\hline Esophageal tumor advanced & $\mathrm{PO}$ & + & $N$ & SU & SU/RE & SU \\
\hline Esophageal tumor intramural & $\mathrm{PO} / \mathrm{SU}$ & + & SU & ++ & + & SU \\
\hline Cardia/gastric tumor early & $\mathrm{PO}$ & + & ++ & ++ & SU & SU \\
\hline Cardia/gastric tumor advanced & $\mathrm{PO}$ & + & $\mathrm{N}$ & SU & SU/RE & SU \\
\hline Cardia/gastric tumor intramural & $\mathrm{PO} / \mathrm{SU}$ & + & SU & ++ & + & SU \\
\hline Duodenal tumor early & $\mathrm{PO} / \mathrm{SU}$ & + & + & ++ & SU & SU \\
\hline Bariatric surgery & $\mathrm{PO}$ & SU & SU & $\mathrm{N}$ & + & SU \\
\hline
\end{tabular}

$S U$ - selective use, + -recommended, $R E$ - requires evaluation, ++ - strongly recommended, $N$ - not recommended, $P O$ - preoperative evaluation. 
$[1,86]$. Following the literature, they include esophageal atresia, tracheoesophageal fistulae, esophageal diverticula and perforations, gastroesophageal reflux disease, gastrointestinal bleeding, atypical duodenal and jejunal webs. In both groups, many other possible indications may arise according to the requirements of individual cases.

Morbidity of IOG does not exceed the morbidity of conventional gastroscopy in specific indications. The possibility of surgical control and possible direct surgical therapy has the potential to decrease possible perforation. The observed mortality is usually not attributed to sole endoscopy, as experienced in our cohort.

General recommendations following the literature references and our experience are summarized in Table IV. Further studies should reveal anastomotic testing in oncological cases, studies on reinforcement of the anastomosis, development of new combined minimally invasive resection techniques and pediatric indications for IOG.

\section{Conclusions}

Despite a heterogenic cohort of patients, we distinguish IOG as a meaningful complementary method in the interventional treatment of upper gastrointestinal tract pathology. It allows a decrease in the conversion rate, provides minimally invasive operations and enables individualization of treatment. The IOG requires extensive cooperation between the surgeon and endoscopist and is demanding on technical skills. Education of surgical endoscopists should be standardized. Further studies to evaluate possible wider and interventional indications are recommended.

\section{Conflict of interest}

The authors declare no conflict of interest. References

1. Davenport KP, Mollen KP, Rothenberg SS, et al. Experience with endoscopy and endoscopy-assisted management of pediatric surgical problems: results and lessons. Dis Esophagus 2013; 26: 37-43.

2. Mittendorf EA, Brandt CP. Utility of intraoperative endoscopy: implications for surgical education. Surg Endosc 2002; 16: 703-6.

3. Beger HG, Schwarz A, Bergmann U. Progress in gastrointestinal tract surgery: the impact of gastrointestinal endoscopy. Surg Endosc 2003; 17: 342-50

4. Hazey JW, Dunkin BJ, Melvin WS. Changing attitudes toward endolumenal therapy. Surg Endosc 2007; 21: 445-8.
5. Luigiano C, Ferrera F, Morace C, et al. Endoscopic tattooing of gastrointestinal and pancreatic lesions. Adv Ther 2012; 29: 864-73.

6. Jeong O, Cho SB, Joo YE, et al. Novel technique for intraoperative tumor localization during totally laparoscopic distal gastrectomy: endoscopic autologous blood tattooing. Surg Endosc 2012; 26: $1778-83$.

7. Park DK, Lee HJ, Kim SG, et al. Intraoperative gastroscopy for gastric surgery. Surg Endosc 2005; 19: 1358-61.

8. Kim BS, Yook JH, Kim BS, et al. A simplified technique for tumor localization using preoperative endoscopic clipping and radio-opaque markers during totally laparoscopic gastrectomy. Am Surg 2014; 80: 1266-70.

9. Takeyama H, Hata T, Nishimura J, et al. A novel endoscopic fluorescent clip visible with near-infrared imaging during laparoscopic surgery in a porcine model. Surg Endosc 2014; 28: 1984-90.

10. Wang B, Hu W, Liu J, et al. Gastroscopic image graph: application to noninvasive multitarget tracking under gastroscopy. Comput Math Methods Med 2014; 2014: 974038.

11. Lee JH, Kim JG, Jung HK, et al. Clinical practice guidelines for gastric cancer in Korea: an evidence-based approach. J Gastric Cancer 2014; 14: 87-104.

12. Stašek M, Tozzi di Angelo I, Aujeský R, et al. Endosonography of the oesophagus in the diagnosis and treatment of oesophageal tumours. Rozhl Chir 2012; 91: 357-61.

13. Mattioli S, Lugaresi ML, Constantini M, et al. The short esophagus: intraoperative assessment of esophageal length. J Thorac Cardiovasc Surg 2008; 136: 834-41.

14. Pearson FG. Expert commentary: a multicenter study to define the incidence of short esophagus in surgical patients with gastroesophageal reflux disease. J Thorac Cardiovasc Surg 2008; 136: 842.

15. Mattioli S, Lugaresi M, Ruffato A, et al. Collis-Nissen gastroplasty for short oesophagus. Multimed Man Cardiothorac Surg 2015; 2015: pii: mmv032. doi: 10.1093/mmcts/mmv032.

16. Becerril-Martínez G, Decanini-Terán C, Spaventa-lbarrola A, et al. Intraoperative endoscopy in laparoscopic fundoplications. Cir Cir 2006; 74: 95-9.

17. Del Genio G, Rossetti G, Brusciano L, et al. Laparoscopic Nissen-Rossetti fundoplication with routine use of intraoperative endoscopy and manometry: technical aspects of a standardized technique. World J Surg 2007; 31: 1099-106.

18. Lázár G, Szentpáli K, Paszt A. Minimally invasive surgical treatment for mid-esophageal and epiphrenic diverticula. Magy Seb 2005; 58: 352-6.

19. Gonzalez-Calatayud M, Targarona EM, Balague C, et al. Minimally invasive therapy for epiphrenic diverticula: systematic review of literature and report of six cases. J Minim Access Surg 2014; 10: 169-74.

20. Papanivelu C, Rangarajan M, Senthilkumar R, et al. Combined thoracoscopic and endoscopic management of mid-esophageal benign lesions: use of the prone patient position: thoracoscopic surgery for mid-esophageal benign tumors and diverticula. Surg Endosc 2008; 22: 250-4.

21. Brangewitz M, Voigtländer T, Helfritz FA, et al. Endoscopic closure of esophageal intrathoracic leaks: stent versus endoscopic vacuum-assisted closure, a retrospective analysis. Endoscopy 2013; 45: 433-8. 
22. Haito-Chavez Y, Law JK, Kratt T, et al. International multicenter experience with an over-the-scope clipping device for endoscopic management of Gl defects (with video). Gastrointest Endosc 2014; 80: 610-22.

23. Chang J, Sharma G, Boules M, et al. Endoscopic stents in the management of anastomotic complications after foregut surgery: new applications and techniques. Surg Obes Relat Dis 2016; 12: 1373-81.

24. Ahn JY, Jung HY, Choi JY, et al. Benign bronchoesophageal fistula in adults: endoscopic closure as primary treatment. Gut Liver 2010; 4: 508-13.

25. Rustagi T, McCarty TR, Aslanian HR. Endoscopic treatment of gastrointestinal perforations, leaks, and fistulae. J Clin Gastroenterol 2015; 49: 804-9.

26. Kuwano H, Kitamura K, Baba K, et al. Determination of the resection line in early esophageal cancer using intraoperative endoscopic examination with Lugol staining. J Surg Oncol 1992; 50: $149-52$.

27. Sgourakis G, Gockel I, Lang H. Endoscopic and surgical resection of $\mathrm{T} 1 \mathrm{a} / \mathrm{T} 1 \mathrm{~b}$ esophageal neoplasms: a systematic review. World J Gastroenterol 2013; 19: 1424-37.

28. Isomoto H, Yamaguchi N, Minami H, et al. Management of complications associated with endoscopic submucosal dissection/ endoscopic mucosal resection for esophageal cancer. Dig Endosc 2013; 25 Suppl 1: 29-38.

29. Hachey KJ, Gilmore DM, Armstrong KW, et al. Safety and feasibility of near-infrared image-guided lymphatic mapping of regional lymph nodes in esophageal cancer. J Thorac Cardiovasc Surg 2016; 152: 546-54.

30. Ntourakis D, Mavrogenis G. Cooperative laparoscopic endoscopic and hybrid laparoscopic surgery for upper gastrointestinal tumors: current status. World J Gastroenterol 2015; 21 12482-97.

31. Hayashi H, Iwasaki A, Kato F, et al. Thoracoscopy and intraoperative upper gastrointestinal endoscopy was effective for Boerhaave syndrome: report of a case. Kyobu Geka 2005; 58: 419-21.

32. Bingener J, Loomis EA, Gostout CJ, et al. Feasibility of NOTES omental plug repair of perforated peptic ulcers: results from a clinical pilot trial. Surg Endosc 2013; 27: 2201-8.

33. Sato $H$, Inoue $H$, Ikeda $H$, et al. Clinical experience of esophageal perforation occurring with endoscopic submucosal dissection. Dis Esophagus 2014; 27: 617-22.

34. Miyahara K, Iwakiri R, Shimoda R, et al. Perforation and postoperative bleeding of endoscopic submucosal dissection in gastric tumors: analysis of 1190 lesions in low- and high-volume centers in Saga, Japan. Digestion 2012; 86: 273-80.

35. Hanaoka N, Uedo N, Ishihara R, et al. Clinical features and outcomes of delayed perforation after endoscopic submucosal dissection for early gastric cancer. Endoscopy 2010; 42: 1112-5.

36. Isomoto $H$, Yamaguchi N, Minami H. Management of complications associated with endoscopic submucosal dissection/endoscopic mucosal resection for esophageal cancer. Dig Endosc 2013; 25 Suppl 1: 29-38.

37. Abe N, Takeuchi H, Yanagida O, et al. Surgical indications and procedures for bleeding peptic ulcer. Dig Endosc 2010; 22 Suppl 1: S35.
38. Grisendi A, Lonardo A, Della Casa G, et al. Combined endoscopic and surgical management of Dieulafoy vascular malformation. J Am Coll Surg 1994; 179: 182-6.

39. Tonea A, Andrei S, Andronesi D, et al. Difficulties in diagnosis and surgical treatment of the angiodysplasia of the gastrointestinal tract. Chirurgia (Bucur) 2008; 103: 513-28.

40. Loveček M, Skalický P, Köcher $M$, et al. Postpancreatectomy haemorrhage (PPH), prevalence, diagnosis and management. Rozhl Chir 2016; 95: 350-7.

41. Roulin D, Cerantola Y, Demartines N, et al. Systematic review of delayed postoperative hemorrhage after pancreatic resection. J Gastrointest Surg 2011; 15: 1055-62.

42. García-García ML, Martín-Lorenzo JG, Torralba-Martínez JA, et al. Emergency endoscopy for gastrointestinal bleeding after bariatric surgery. Therapeutic algorithm. Cir Esp 2015; 93 : 97-104.

43. Schulz HJ, Schmidt H. Intraoperative enteroscopy. Gastrointest Endosc Clin N Am 2009; 19: 371-9.

44. Kopáčová M, Bureš J, Vykouřil L, et al. Intraoperative enteroscopy: ten years' experience at a single tertiary center. Surg Endosc 2007; 21: 1111-6.

45. Raphaeli T, Menon R. Current treatment of lower gastrointestinal hemorrhage. Clin Colon Rectal Surg 2012; 25: 219-27.

46. Udd M, Lindström O, Mustonen $\mathrm{H}$, et al. Assessment of indications for percutaneous endoscopic gastrostomy: development of a predictive model. Scand J Gastroenterol 2015; 50: 245-52.

47. Nugent B, Lewis S, O'Sullivan JM. Enteral feeding methods for nutritional management in patients with head and neck cancers being treated with radiotherapy and/or chemotherapy. Cochrane Database Syst Rev 2013; 1: CD007904.

48. Han NY, Park BK, Park SS, et al. Modified fusion imaging combining CT gastrography and CT angiography: an initial experience of preoperative mapping prior to laparoscopic exogastric wedge resection of small $(<3 \mathrm{~cm})$ gastric submucosal lesions. Abdom Imaging 2014; 39: 242-50.

49. Wilhelm D, von Delius S, Burian M, et al. Simultaneous use of laparoscopy and endoscopy for minimally invasive resection of gastric subepithelial masses - analysis of 93 interventions. World J Surg 2008; 32: 1021-8.

50. Granger SR, Rollins MD, Mulvihill SJ, et al. Lessons learned from laparoscopic treatment of gastric and gastroesophageal junction stromal cell tumors. Surg Endosc 2006; 20: 1299-304.

51. Kim SY, Kim KO. Management of gastric subepithelial tumors: the role of endoscopy. World J Gastrointest Endosc 2016; 8: 418-24.

52. Qiu WQ, Zhuang J, Wang M, et al. Minimally invasive treatment of laparoscopic and endoscopic cooperative surgery for patients with gastric gastrointestinal stromal tumors. J Dig Dis 2013; 14: 469-73.

53. Jeong IH, Kim JH, Lee SR, et al. Minimally invasive treatment of gastric gastrointestinal stromal tumors: laparoscopic and endoscopic approach. Surg Laparosc Endosc Percutan Tech 2012; 22: 244-50.

54. Balde Al, Chen T, Hu Y, et al. Safety analysis of laparoscopic endoscopic cooperative surgery versus endoscopic submucosal dissection for selected gastric gastrointestinal stromal tumors: a propensity score-matched study. Surg Endosc 2017; 31: 843-51. 
55. Hiki N, Nunobe S, Matsuda T, et al. Laparoscopic endoscopic cooperative surgery. Dig Endosc 2015; 27: 197-204.

56. Klingman MD. Intraoperative endoscopic pneumatic testing for gastrojejunal anastomotic integrity during laparoscopic Rouxen-Y gastric bypass. Surg Endosc 2007; 21: 1403-5.

57. Jeong ID, Jung SW, Bang SJ, et al. Endoscopic enucleation for gastric subepithelial tumors originating in the muscularis propria layer. Surg Endosc 2011; 25: 468-74.

58. Irino T, Nunobe S, Hiki N, et al. Laparoscopic-endoscopic cooperative surgery for duodenal tumors: a unique procedure that helps ensure the safety of endoscopic submucosal dissection. Endoscopy 2015; 47: 349-51.

59. Ichikawa D, Komatsu S, Dohi O, et al. Laparoscopic and endoscopic co-operative surgery for non-ampullary duodenal tumors. World J Gastroenterol 2016; 22: 10424-31.

60. Kakushima N, Kanemoto H, Tanaka M, et al. Treatment for superficial non-ampullary duodenal epithelial tumors. World J Gastroenterol 2014; 20: 12501-8.

61. Kyuno D, Ohno K, Katsuki S, et al. Laparoscopic-endoscopic cooperative surgery is a safe and effective treatment for superficial nonampullary duodenal tumors. Asian J Endosc Surg 2015; 8: 461-4.

62. Ohata K, Murakami M, Yamazaki K, et al. Feasibility of endoscopy-assisted laparoscopic full-thickness resection for superficial duodenal neoplasms. Sci World J 2014; 16: 239627.

63. Jung MK, Cho CM, Park SY, et al. Endoscopic resection of ampullary neoplasms: a single-center experience. Surg Endosc 2009; 23: 2568-74.

64. Saurin JC, Chavaillon A, Napoléon B, et al. Long-term follow-up of patients with endoscopic treatment of sporadic adenomas of the papilla of vater. Endoscopy 2003; 35: 402-6.

65. Norton JA. Intraoperative methods to stage and localize pancreatic and duodenal tumors. Ann Oncol 1999; 10 Suppl 4: 182-4.

66. Doi S, Yasuda I, Nakashima M, et al. Endoscopic ultrasound-guided fine-needle aspiration of lesions near the aortoiliac bifurcation via an upper gastrointestinal approach. J Gastroenterol Hepatol 2011; 26: 1717-20.

67. Dubravcsik Z, Serényi P, Madácsy L, et al. Endoscopic ultrasound-guided fine needle aspiration cytology in the mediastinum. Orv Hetil 2013; 154: 338-44.

68. Lochowski MP, Brzezinski D, Kozak J. Videothoracoscopy in the treatment of benign neurogenic tumours of the posterior mediastinum. Videosurgery Miniinv 2014; 9: 315-8.

69. Carus T, Dammer R. Laparoscop fluorescence angiography with indocyanine green to control the perfusion of gastrointestina anastomoses intraoperatively. Surg Technol Int 2012; 22: 27-32.

70. Sethi M, Zagzag J, Patel K, et al. Intraoperative leak testing has no correlation with leak after laparoscopic sleeve gastrectomy. Surg Endosc 2016; 30: 883-91.

71. Mohos E, Schmaldienst E, Richter D, et al. Examination of the efficacy and safety of intraoperative gastroscopic testing of the gastrojejunal anastomosis in laparoscopic Roux $Y$ gastric bypass surgery. Obes Surg 2011; 21: 1592-6.

72. Haddad A, Tapazoglou N, Singh K, et al. Role of intraoperative esophagogastroenteroscopy in minimizing gastrojejunostomy-related morbidity: experience with 2,311 laparoscopic gastric bypasses with linear stapler anastomosis. Obes Surg 2012; 22: 1928-33.
73. Nishikawa K, Yanaga K, Kashiwagi H, et al. Significance of intraoperative endoscopy in total gastrectomy for gastric cancer. Surg Endosc 2010; 24: 2633-6.

74. Tani T, Sonoda H, Tani M. Sentinel lymph node navigation surgery for gastric cancer: does it really benefit the patient? World J Gastroenterol 2016; 22: 2894-9.

75. Gockel I, Sgourakis G, Lyros O, et al. Risk of lymph node metastasis in submucosal esophageal cancer: a review of surgically resected patients. Expert Rev Gastroenterol Hepatol 2011; 5: 371-84.

76. Yuasa Y, Seike J, Yoshida T, et al. Sentinel lymph node biopsy using intraoperative indocyanine green fluorescence imaging navigated with preoperative CT lymphography for superficial esophageal cancer. Ann Surg Oncol 2012; 19: 486-93.

77. Takeuchi H, Goto O, Yahagi N, et al. Function-preserving gastrectomy based on the sentinel node concept in early gastric cancer. Gastric Cancer 2017; 20 (Suppl 1): 53-9.

78. Adikibi BT, MacKinlay GA, Munro FD, et al. Intraoperative upper Gl endoscopy ensures an adequate laparoscopic Heller's myotomy. J Laparoendosc Adv Surg Tech A 2009; 19: 687-9.

79. Alves A, Perniceni T, Godeberge P, et al. Laparoscopic Heller's cardiomyotomy in achalasia. Is intraoperative endoscopy useful, and why? Surg Endosc 1999; 13: 600-3.

80. Di Martino N, Marano L, Torelli F, et al. The calibrated laparoscopic Heller myotomy with fundoplication. Ann Ital Chir 2013; 84: 505-10.

81. Papanivelu C, Rangarajan M, Shetty AR, et al. Laparoscopic suture gastropexy for gastric volvulus: a report of 14 cases. Surg Endosc 2007; 21: 863-6.

82. Barillaro I, Grassi V, De Sol A, et al. Endoscopic rendez-vous after damage control surgery in treatment of retroperitoneal abscess from perforated duodenal diverticulum: a technical note and literature review. World J Emerg Surg 2013; 8: 26.

83. Gong EJ, Jung HY, Kim DH, et al. Intraoperative endoscopic removal of a duodenal bezoar in a patient with intestinal malrotation. Gastrointest Endosc 2014; 80: 346; discussion 347.

84. Kobryn K, Kozieł S, Patkowski W, et al. Intraoperative salvage endoscopy performed during orthotopic liver transplantation due to esophageal bleeding. Videosurgery Miniinv 2015; 10: 472-6.

85. Park J, Ellis B, Juergens C. Laparoscopic resection of Osler-Weber-Rendu lesion. JSLS 2008; 12: 180-2.

86. Morcate JJ, Willital GH, Tsokas J. Intraoperative endoscopy in pediatric surgery: indications and results. Cir Pediatr 1996; 9: 55-9.

Received: 30.06.2017, accepted: 16.10.2017. 